\title{
Major proteins of the goat milk fat globule membrane
}

\author{
C. Cebo, ${ }^{* 1}$ H. Caillat, $†$ F. Bouvier, $\ddagger$ and P. Martin* \\ *INRA, UMR1313 Unité Génétique Animale et Biologie Intégrative, F-78350 Jouy-en-Josas, France \\ †INRA, UR631 Station d'Amélioration Génétique des Animaux, F-31426 Castanet-Tolosan, France \\ fINRA, UE332 Domaine de Bourges, F18390 Osmoy, France
}

\section{ABSTRACT}

Fat is present in milk as droplets of triglycerides surrounded by a complex membrane derived from the mammary epithelial cell called milk fat globule membrane (MFGM). Although numerous studies have been published on human or bovine MFGM proteins, to date few studies exist on MFGM proteins from goat milk. The objective of this study was thus to investigate the protein composition of the goat MFGM. Milk fat globule membrane proteins from goat milk were separated by $6 \%$ and $10 \%$ sodium dodecyl sulfate-PAGE and were Coomassie or periodic acid-Schiff stained. Most of MFGM proteins [mucin-1, fatty acid synthase, xanthine oxidase, butyrophilin, lactadherin (MFG EGF-8, MFG-E8), and adipophilin] already described in cow milk were identified in goat milk using peptide mass fingerprinting. In addition, lectin staining provided a preliminary characterization of carbohydrate structures occurring on MFGM proteins from goat milk depending on $\alpha_{S_{1}}$-casein genotype and lactation stage. We provide here first evidence of the presence of O-glycans on fatty acid synthase and xanthine oxidase from goat milk. A prominent difference between the cow and the goat species was demonstrated for lactadherin. Indeed, whereas 2 polypeptide chains were easily identified by peptide mass fingerprinting matrix-assisted laser desorption/ionization-time of flight analysis within bovine MFGM proteins, lactadherin from goat milk consisted of a single polypeptide chain. Another striking observation was the presence of caseins associated with MFGM preparations from goat milk, whereas virtually no caseins were found in MFGM extracts from bovine milk. Taken together, these observations strongly support the existence of a singular secretion mode previously hypothesized in the goat.

Key words: milk fat globule membrane, glycoprotein, lactadherin, secretion

Received August 12, 2009.

Accepted November 11, 2009.

${ }^{1}$ Corresponding author: christelle.cebo@jouy.inra.fr

\section{INTRODUCTION}

Goat milk accounts for more than $50 \%$ of milk production in developing countries where cow milk is not readily affordable. In Europe, where goat milk is processed mostly for cheese manufacture, its production increased by $12 \%$ over the past $30 \mathrm{yr}$ (Haenlein, 2001). In addition to its economic importance, goat milk may be of great nutritional interest, especially regarding the highly bioactive oligosaccharide fraction (Boehm and Stahl, 2007). Supporting this observation, it has been recently demonstrated that goat milk oligosaccharides possess antiinflammatory properties in a rodent model of hapten-induced colitis (Daddaoua et al., 2006; Martinez-Ferez et al., 2006). Similarly, many health benefits can been attributed to the glycoproteins of the milk fat globule membrane (MFGM), the surrounding complex structure deriving from the mammary epithelial cell (MEC), which envelops the fat globule during the secretion process (Schroten, 1998; Dewettinck et al., 2008). Indeed, antiinfectious, anticancer, and anticholesterolemic effects have been described for bovine MFGM components (Spitsberg, 2005), thus highlighting the need to better characterize this fraction, which represents only $1 \%$ of total milk proteins. Major MFGM proteins from human or bovine milk have been extensively reviewed (Mather, 2000) and several proteomic studies on MFGM have been recently published, either for bovine, equine, or buffalo milk (Reinhardt and Lippolis, 2006; Barello et al., 2008; D'Ambrosio et al., 2008). In bovine milk, using a proteomic approach based on liquid chromatography connected with tandem mass spectrometry, Reinhardt and Lippolis (2006) recently identified more than 120 proteins with diverse functions such as trafficking, cell signaling, or immune response. Moreover, they characterized changes in the bovine MFGM proteome during the transition from colostrum to mature milk (Reinhardt and Lippolis, 2008). However, MFGM proteins from goat milk are poorly characterized compared with their bovine or human counterparts, with the exception of mucins, which are high molecular weight proteins that contain more than $50 \%$ carbohydrates and that have well-recognized antiinfectious effects. In the goat, mucin-1 and, more 
recently, mucin- 15 have been characterized either at the DNA or protein level (Campana et al., 1992; Patton, 1999; Sacchi et al., 2004; Pallesen et al., 2008). However, to date, nonmucin MFGM proteins are not clearly identified in goat milk.

The purpose of this study was thus to describe the MFGM protein fraction of goat milk. Milk fat globule membrane proteins were separated by SDS-PAGE and were then Coomassie or periodic acid-Schiff (PAS) stained. Most of the MFGM proteins already described in bovine milk were identified from goat MFGM by peptide mass fingerprinting (PMF) mass spectrometry (MS), and their carbohydrate contents was analyzed by lectin staining. Prominent differences were found between the cow and the goat species. Finally, some aspects of our findings are discussed in relation to milk secretion pathways in the goat.

\section{MATERIALS AND METHODS}

\section{Animals and Milk Samples}

Individual milk samples (evening + morning milking) were collected from 8 primiparous goats (4 produced high $\alpha_{\mathrm{S}^{-}} \mathrm{CN}, 4$ were $\alpha_{\mathrm{S} 1}-\mathrm{CN}$ null $)$ at early $(26 \pm 9 \mathrm{~d})$, mid $(135 \pm 9 \mathrm{~d})$, and late $(250 \pm 9 \mathrm{~d}$ postpartum) lactation stages on INRA Bourges-Domaine de Galle experimental farm (Avord, France). Preservatives (0.05 $\mathrm{g} / \mathrm{L}$ of potassium dichromate, $10 \mathrm{~m} M$-amino caproic acid, and $10 \mu M$ phenylmethylsulfonyl fluoride) were added to milk immediately after milking to prevent proteolysis of samples. Milk samples were stored at $-20^{\circ} \mathrm{C}$ in 50-mL aliquots. For protein extraction, milk samples were incubated for $30 \mathrm{~min}$ at $37^{\circ} \mathrm{C}$ and centrifuged at $2,000 \times g$ for $15 \mathrm{~min}$ at $20^{\circ} \mathrm{C}$. Samples were incubated for $30 \mathrm{~min}$ at $4^{\circ} \mathrm{C}$ to help with skimming. Fat globules were recovered in the supernatant layer and washed 3 times with $0.9 \%$ (wt/vol) $\mathrm{NaCl}$ to remove residual CN and whey proteins that had adsorbed to fat globules. Twelve bovine milk samples from 2 individuals were similarly handled for MFGM protein extraction.

\section{Extraction and Analysis of MFGM Proteins}

Milk fat globule membrane proteins were extracted from milk fat with an SDS-containing solution as described previously (Fortunato et al., 2003) with some modifications. Briefly, lysis buffer $(63 \mathrm{mM}$ Tris- $\mathrm{HCl}$, $\mathrm{pH} 9,2 \%$ SDS) supplemented with a protease inhibitor cocktail (Complete Mini, EDTA-free, Roche Diagnostics, Basel, Switzerland) was added to washed fat globules at a concentration of $1 \mathrm{~mL} / \mathrm{g}$ of fat, incubated for $1 \mathrm{~h}$ at room temperature with periodical vortexing, and centrifuged at $10,000 \times g$ for $10 \mathrm{~min}$. The floating cream layer was removed and lysates were centrifuged again at $10,000 \times g$ for $10 \mathrm{~min}$ and then stored at $-20^{\circ} \mathrm{C}$ (or $-80^{\circ} \mathrm{C}$ for long-term storage) for further analysis. Protein concentration (Lowry's method) was assessed with the Bio-Rad RC-DC Protein Assay (Bio-Rad Laboratories, Hercules, CA) according to the instructions of the manufacturer. Proteins were resolved by SDS-PAGE, stained with Bio-Safe Coomassie (Bio-Rad Laboratories), or electrotransferred onto nitrocellulose for immunoblotting with lectins.

\section{PAS Staining}

For total glycoprotein analysis, $50 \mu \mathrm{g}$ of proteins were separated on $6 \%$ acrylamide gels $(4.5 \%$ acrylamide for the stacking gel) and revealed with the Schiff reagent (Sigma-Aldrich, St. Louis, MO) in accordance with the protocol of the manufacturer. Briefly, gels were fixed overnight in $40 \%$ ethanol $/ 7 \%$ acetic acid. Gels were then washed 2 times (30 min each) with fresh fixative solution. Carbohydrates were oxidized for $1 \mathrm{hr}$ by immersing gels in a solution of $1 \%$ periodic acid $/ 3 \%$ acetic acid, and were then washed 10 times (10 min each) with water to remove traces of periodic acid. Gels were immersed for $1 \mathrm{~h}$ in the Schiff's reagent in the dark to reveal the glycoprotein bands, and were then washed for $15 \mathrm{~min}$ with water. Images were immediately acquired after washing.

\section{Analysis and Identification of Proteins from 1-Dimensional PAGE by Matrix-Assisted Laser Desorption/lonization-Time of Flight MS}

Proteins were excised from 1-dimensional gel, and gel pieces were washed 2 times in ultrapure water followed by 2 times in $50 \%$ acetonitrile and $50 \mathrm{mM}$ ammonium bicarbonate $\left[\mathrm{NH}_{4} \mathrm{HCO}_{3}\right.$ ( $\left.\left.\mathrm{vol} / \mathrm{vol}\right)\right]$. After gel-drying for $10 \mathrm{~min}$, the digestion was performed in $30 \mu \mathrm{L}$ of $50 \mathrm{mM} \mathrm{NH} \mathrm{NHCO}_{3}(\mathrm{pH}$ 8.0) with $0.2 \mu \mathrm{g}$ of modified trypsin (sequencing grade, Promega, Madison, WI) for $16 \mathrm{~h}$ at $37^{\circ} \mathrm{C}$. The identity of peptides was obtained by matrix-assisted laser desorption/ionization-time of flight (MALDI-TOF) MS (Voyager DE super STR, Applied Biosystems, Foster City, CA) equipped with a nitrogen laser emitting at $337 \mathrm{~nm}$. One microliter of tryptic digest was mixed on the stainless steel MALDI plate with $1 \mu \mathrm{L}$ of CHCA ( $\alpha$-cyano-4-hydroxycinnamic acid, Sigma-Aldrich) at $5 \mathrm{mg} / \mathrm{mL}$ in acetonitrile/0.3\% trifluoroacetic acid (vol/vol) and dried at room temperature. Spectra were recorded in positive reflector mode with $20 \mathrm{kV}$ as accelerating voltage, a delayed extraction time of $120 \mathrm{~ns}$, and a $63 \%$ grid voltage. Spectra were calibrated using internal calibration comprising tryptic autolysis peptides $\left([\mathrm{M}+\mathrm{H}]^{+}=842.51\right.$ and $[\mathrm{M}+\mathrm{H}]^{+}=$ 
2,211.11). Mass spectra were treated by Data Explorer 4.2 (Applied Biosystems) with the following parameters: baseline correction, noise filter/smooth (noise removal of 2), and peak resolution of 10,000. Spectral profiles were collected in the mass range of mass:charge ratio $=$ 800 to 3,000 Da. All peptide masses were assumed to be monoisotopic and protonated molecular ions $[\mathrm{M}+\mathrm{H}]^{+}$. Proteins were identified among Swiss-Prot and TrEMBL databases using the Aldente Peptide Mass Fingerprinting tool from Expasy (http://www.expasy.org/ tools/aldente/) with the following parameters: trypsin specificity, one missed cleavage, $30 \mathrm{ppm}$ mass accuracy, and carbamidomethylation and methionine oxidation as fixed and variable modifications, respectively.

\section{Lectin Staining}

For lectin analysis, MFGM proteins were resolved by $6 \%$ SDS-PAGE and electrotransferred onto nitrocellulose. Blots were saturated for $1 \mathrm{~h}$ at room temperature with Tris-buffered saline (TBS) 5\% Tween 20 and then probed for $2 \mathrm{~h}$ at room temperature with the following biotin-conjugated lectins: concanavalin A (ConA; $7.5 \mathrm{ng} / \mathrm{mL})$, Sambucus nigra lectin (SNA; $3 \mathrm{ng} / \mathrm{mL}$ ), Maackia amurensis lectin II (MALII; $30 \mathrm{ng} / \mathrm{mL}$ ), and peanut agglutinin (PNA; $30 \mathrm{ng} / \mathrm{mL}$ ), all from Vector Laboratories (Burlingame, CA). Blots were washed extensively with TBS 1\% Tween 20 and then incubated for $1 \mathrm{~h}$ with $10 \mu \mathrm{g}$ of horseradish peroxidase-streptavidin in TBS 1\% Tween 20. After extensive washing, blots were revealed with the enhanced chemiluminescence system (GE Healthcare, Waukesha, WI). Sambucus nigra lectin binds preferentially to sialic acids attached to terminal galactose in $(\alpha 2,6)$ and, to a lesser extent, $(\alpha 2,3)$ linkage, whereas MALII staining is specific for $(\alpha 2,3)$-linked sialic acids. Peanut agglutinin lectin binds to galactose$\beta 1,3-\mathrm{N}$-acetylgalactosamine structure, commonly found in O-linked glycans. Concanavalin A binds to $\alpha$-linked mannose, as found in N-glycans. Bovine serum albumin was taken as a negative control for lectin blotting experiments, and no binding was observed for this protein for all lectins studied in this study.

\section{Immunoblotting Experiments}

For immunoblotting, $25 \mu \mathrm{g}$ of MFGM protein was resolved by $10 \%$ SDS-PAGE and electrotransferred onto nitrocellulose. Blots were saturated with $5 \%$ nonfat dry milk in TBS and probed for $2 \mathrm{~h}$ at room temperature in TBS 0.1\% Tween 20 (Sigma-Aldrich) with antibodies against mouse adipophilin or bovine butyrophilin (1/5,000; both from Progen, Toowong, Australia). Blots were extensively washed in TBS $0.1 \%$ Tween 20 and incubated with appropriate secondary antibodies
(1/5,000; Sigma-Aldrich). Immunocomplexes were then revealed by the ECL system (GE Healthcare).

\section{RESULTS AND DISCUSSION}

\section{Identification of Major MFGM Proteins from Goat Milk}

A representative pattern of goat MFGM proteins resolved in 10 and 6\% SDS-PAGE gels after Coomassie staining is shown in Figures $1 \mathrm{~A}$ and $1 \mathrm{~B}$ (lanes 3-4), respectively. The protein profile displays several major bands identified by PMF MALDI-TOF analysis as fatty acid synthase (FAS), xanthine oxidase (XO), butyrophilin (BTN1A1), lactadherin (LDH), and adipophilin (ADRP). In addition, some minor bands resulting from the previously described proteolysis events of BTN1A1 (Mather, 2000) or to complexes between BTN1A1 and XO were also observed. After PAS staining, which revealed only proteins with high carbohydrate contents, 4 bands could be easily visualized for goat MFGM glycoproteins (Figure 2; lanes 3-4). Among PAS-stained proteins, only LDH and BTN1A1 were identified by PMF MALDI-TOF analysis. Bands corresponding to mucin-1 and to an $80-\mathrm{kDa}$ protein so far not identified, probably corresponding to the bovine CD36 protein, were also visualized. These proteins were not identified by PMF MALDI-TOF analysis, probably because of the presence of large quantities of carbohydrates inhibiting trypsin digestion, or impairing ionization of glycopeptides during MS analyses, or both. However, we confirmed the polymorphic aspect of goat mucin-1 (presence of 1 or 2 equally stained bands for mucin-1) previously demonstrated by others (Campana et al., 1992). In addition, we confirmed that, in comparison with its bovine counterpart, the goat mucin would be a considerably larger protein (Figure 2; lanes 1-2 and lanes 3-4). A faint band of about $130 \mathrm{kDa}$ can also be observed corresponding to the PAS III/mucin-15 protein previously identified in bovine MFGM (Pallesen et al., 2002) and, more recently, in the caprine and ovine MFGM (Pallesen et al., 2008). In addition, a high molecular weight material can also be observed in the stacking gel (4.5\% acrylamide) after PAS staining. The presence of this high molecular weight protein has already been described in bovine milk. However, limited information is available on this glycoprotein, which is therefore named mucin-X (Patton, 2001; Liu et al., 2005).

\section{Comparison of the MFGM Proteins Between Goat and Cow}

A prominent difference between the cow and the goat species was observed for $\mathrm{LDH}$. In the cow, $\mathrm{LDH}$, also 

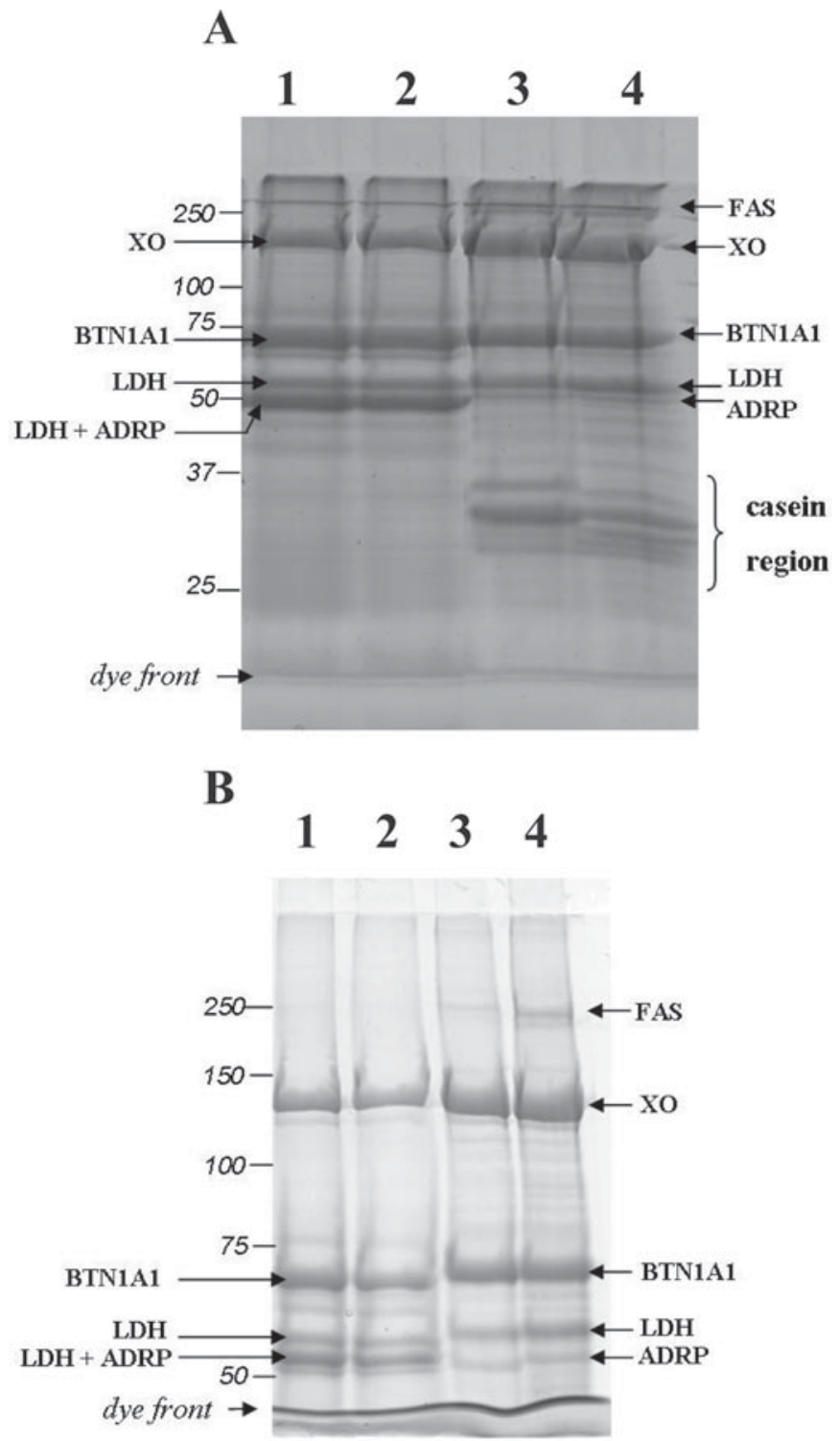

Figure 1. Representative pattern of goat milk fat globule membrane (MFGM) proteins in SDS-PAGE. Twenty-five micrograms of MFGM proteins were separated either on A) $10 \%$ or B) $6 \%$ SDSPAGE and stained with Bio-Safe (Bio-Rad Laboratories, Hercules, CA). The MFGM proteins are from bovine (lanes 1-2) and caprine (lanes 3-4) milks. For identification, proteins were gel-digested by 0.2 $\mu \mathrm{g}$ of trypsin, and peptides mixtures were subjected to matrix-assisted laser desorption/ionization-time of flight mass spectrometry analysis. Proteins identified with mass spectrometry were fatty acid synthase [FAS; accession number Q076H7 (Capra hircus)]; xanthine oxidase [XO; accession number A1YZ34 (Capra hircus)]; butyrophilin [BTN1A1; accession number A3EY52 (Capra hircus)]; lactadherin [LDH; accession number Q95114 (Bos taurus)]; and adipophilin [ADRP; accession number A6ZE99 (Ovis aries)]. Positions of protein standards (kDa) are indicated to the left of the panel.

known as PAS 6/7 (accession number Q95114), consists of 2 polypeptides that stain well with Coomassie blue and the PAS reagent. These bands, ranging in size from 52 to $58 \mathrm{kDa}$, correspond to protein isoforms produced by alternative splicing, a long isoform consisting of 427 AA and a short isoform arising from an internal truncation of $52 \mathrm{AA}$, starting from position 169 and extending to position 220 (Hvarregaard et al., 1996). This is the consequence of an exon skipping event (exon 5) occurring during the course of the premessengers maturation process. Limited information is available on caprine LDH (accession number P85297; 12 AA fragment located in the C-terminal part of the protein), and a fulllength sequence for this protein is still missing in the goat species. However, we show here that, in contrast with bovine LDH for which the 2 polypeptide chains are easily identified by PMF MALDI-TOF analysis, LDH from goat milk consists of a single polypeptide chain. Indeed, the presence of LDH in both bands corresponding to bovine PAS 6/7 (Figure 1; lanes 1 and 2) was confirmed by PMF, whereas only 2 distinct bands of $55 \mathrm{kDa}$ and $50 \mathrm{kDa}$ in Coomassie-stained gels for $\mathrm{LDH}$ and ADRP, respectively, were characterized in the MFGM from goat milk (Figure 1; lanes 3-4). Accordingly, in PAS-stained gels, only the upper band corresponding to the heavily glycosylated LDH from goat milk is visualized, whereas 2 bands corresponding to the 2 differently processed transcripts are visible for bovine LDH (Figure 2; compare lanes 1-2 and lanes $3-4)$. Growing biological roles are attributed to LDH, including adhesive mechanisms, apoptosis, spermatozoa capacitation, and mammary gland involution after lactation (Petrunkina et al., 2003; Hanayama and Nagata, 2005; Shi et al., 2006). In addition, by using differential gel electrophoresis-based proteomics, we provide the first evidence of the involvement of LDH in fat globule secretion from the MEC, thus suggesting a key function for this protein in milk synthesis [C. Cebo, C. Beauvallet (INRA UMR 1313 Unité Génétique Animale et Biologie Intégrative, Equipe Lait, Génome et Santé, Jouy-en-Josas, France; INRA Plateforme ICE, IsoCell Express, Jouy-en-Josas, France), C. Lopez (INRA UMR 1253 Science et Technologie du Lait et de l'Oeuf, Rennes, France), C. Henry (INRA Platforme d'Analyse Protéomique Paris Sud Ouest, Jouy-en-Josas, France), C. Bevilacqua (INRA UMR 1313 Unité Génétique Animale et Biologie Intégrative, Equipe Lait, Génome et Santé; INRA Plateforme ICE, Iso-Cell Express), H. Caillat, and P. Martin; unpublished data].

Another striking observation was the presence of $\mathrm{CN}$ in MFGM protein preparations from goat milk as compared with those from bovine milk (Figure 1A). Although fat globules from cow and goat milk were similarly handled, 10\% SDS-PAGE analysis of MFGM proteins from goat milk reveals the presence of $\mathrm{CN}$ in goat samples, whereas virtually no $\mathrm{CN}$ were detected as associated with fat globule proteins from bovine milk (Figure 1A; compare lanes 1-2 and lanes 3-4). 


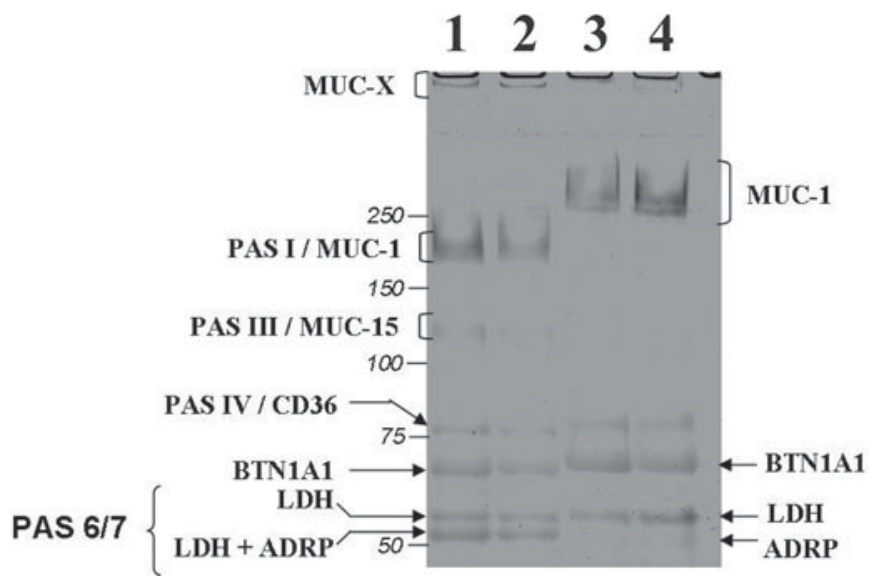

Figure 2. Periodic acid-Schiff (PAS) staining of goat milk fat globule membrane proteins. Fifty micrograms of milk fat globule membrane proteins from bovine (lanes 1-2) or caprine (lanes 3-4) milks were loaded on $6 \%$ SDS-PAGE and stained with periodic acid-Schiff reagent. Because of codominant expression of variable-sized alleles, 1 or 2 equally stained bands for mucin-1 are visualized from individual milk samples. Positions of protein standards $(\mathrm{kDa})$ are indicated to the left of the panel. MUC = mucin; CD36 = cluster of differentiation 36; BTN1A1 = butyrophilin; LDH = lactadherin; ADRP = adipophilin;

These observations argue for a singular secretion mode in the goat. Though growing information is arising from biochemical characterization of MFGM proteins (Mather, 2000) and from electronic microscopy studies on milk fat globules (Robenek et al., 2006a,b), little is known about precise mechanisms leading to milk secretion, especially to milk fat secretion. Indeed, to date, it is not clear whether cytoplasmic lipid droplets first originating from the endoplasmic reticulum (ER) are progressively enveloped by the plasma membrane or whether cytoplasmic lipid droplets are extruded from the MEC by fusion of peripherally associated secretory vesicles with the plasma membrane (McManaman et al., 2007). However, a singular milk secretion process has already been suggested in the goat. An apocrine process (consisting of various-sized fragments of secretory cells containing cytoplasmic inclusions known as cytoplasmic crescents) is suggested for the goat species, whereas a merocrine process (consisting of secretion of milk components without loss of cytoplasm) is proposed for the cow species. Furthermore, it has been proposed for the goat species that this mechanism might be dependent upon the $\alpha_{\mathrm{S}^{-}} \mathrm{CN}$ genotype (Neveu et al., 2002). Here, we clearly showed that CN probably deriving from secretory vesicles were constantly embedded with MFGM preparations from goat milk. By using a label-free, MS-based approach, we additionally showed that more CN were associated with the MFGM protein fraction originating from goats that were $\alpha_{S_{1}-} \mathrm{CN}$ null (homozygous at the CSN1S1 locus), thus suggesting an alternative pathway for milk fat secretion in the animals that were $\alpha_{\mathrm{S}_{1}}-\mathrm{CN}$ defective $[\mathrm{C}$. Cebo, C. Beauvallet (INRA UMR 1313 Unité Génétique Animale et Biologie Intégrative, Equipe Lait, Génome et Santé, Jouy-en-Josas, France; INRA Plateforme ICE, IsoCell Express, Jouy-en-Josas, France), C. Lopez (INRA UMR 1253 Science et Technologie du Lait et de l'Oeuf, Rennes, France), C. Henry (INRA Platforme d'Analyse Protéomique Paris Sud Ouest, Jouy-en-Josas, France), C. Bevilacqua (INRA UMR 1313 Unité Génétique Animale et Biologie Intégrative, Equipe Lait, Génome et Santé; INRA Plateforme ICE, Iso-Cell Express), H. Caillat, and P. Martin; unpublished data]. Finally, the presence of ER-resident proteins found in the milk from goats that were $\alpha_{\mathrm{S} 1}-\mathrm{CN}$ null strongly supports this observation [C. Beauvallet, C. Bevilacqua (both of INRA UMR 1313 Unité Génétique Animale et Biologie Intégrative, Equipe Lait, Génome et Santé, Jouy-en-Josas, France; INRA Plateforme ICE, Iso-Cell Express, Jouyen-Josas, France), B. Badaoui (INRA UMR 1313 Unité Génétique Animale et Biologie Intégrative, Equipe Lait, Génome et Santé), C. Cebo, S. Makhzami, S. Pollet (both of INRA UMR 1313 Unité Génétique Animale et Biologie Intégrative, Equipe Lait, Génome et Santé; INRA Plateforme ICE, Iso-Cell Express), E. Chanat (INRA UR1196, Génomique et Physiologie de la Lactation, Domaine de Vilvert, Jouy-en-Josas, France), and P. Martin; unpublished data]. Taken together, these results open new roads for milk secretion mechanisms in mammals.

\section{Glycosylation of Major Goat MFGM Proteins}

To provide additional information about the carbohydrate structures occurring on goat MFGM proteins, we used lectins with broad specificities for staining approaches. Peanut agglutinin lectin binds to galactose$\beta 1,3-\mathrm{N}$-acetylgalactosamine structure, commonly found in O-linked glycans ( $\mathrm{T}$ antigen), whereas ConA binds to $\alpha$-linked mannose, as found in N-glycans. Thus, both O- and N-glycosylation can be characterized on MFGM glycoproteins. Sialic acids, which are structures found on the surface of the cell and on secreted proteins, possess numerous roles either in adhesion, signaling, or immune response processes (Varki, 2007). We therefore used 2 different lectins, SNA and MALII, to characterize sialic acids on MFGM glycoproteins. SNA lectin binds preferentially to sialic acids attached to terminal galactose in $(\alpha 2,6)$ and, to a lesser extent, $(\alpha 2,3)$ linkage, whereas MALII staining is specific for $(\alpha 2,3)$-linked sialic acids. Both structures can be found either in N- or O-glycans. Binding activities of ConA, PNA, MALII, and SNA lectins to major MFGM glycoproteins from goat milk are summarized in Table 1. Mucin-1, FAS, XO, BTN1A1, and $\mathrm{LDH}$ are revealed by SNA lectin, thus accounting 
Table 1. Lectin binding to major goat milk fat globule membrane proteins ${ }^{1}$

\begin{tabular}{|c|c|c|c|c|}
\hline & ConA & PNA & MALII & SNA \\
\hline $\begin{array}{l}\text { Mucin-X } \\
\text { Mucin-1 } \\
\text { Fatty acid synthase } \\
\text { Xanthine oxidase } \\
\text { Butyrophilin } \\
\text { Lactadherin } \\
\text { Adipophilin }\end{array}$ & $\begin{array}{l}+ \\
+/- \\
+/- \\
+/- \\
+++ \\
+++ \\
+/-\end{array}$ & $\begin{array}{l}+++ \\
++ \\
+ \\
++ \\
+/- \\
+/- \\
+/-\end{array}$ & $\begin{array}{l}++ \\
+++ \\
++ \\
+++ \\
+/- \\
+/- \\
+/-\end{array}$ & $\begin{array}{l}+ \\
+ \\
+ \\
++ \\
+++ \\
+++ \\
+/-\end{array}$ \\
\hline
\end{tabular}

${ }^{1}$ Lectin staining intensities indicate level of binding (ranging from $+=$ significant binding to $+++=$ strong binding) to major goat milk fat globule membrane proteins as identified by peptide mass fingerprinting matrix-assisted laser desorption/ionization-time of flight. Intensities were visually evaluated from blotting experiment results. ConA = concanavalin; PNA = peanut agglutinin; MALII = Maackia amurensis lectin $\mathrm{II} ; \mathrm{SNA}=$ Sambucus nigra lectin.

for the presence of $(\alpha 2,6)$-linked sialic acid chains on these proteins. In contrast, only mucin-1, FAS, and XO are clearly stained by MALII lectin. Thus, in the goat, BTN1A1 and LDH are $(\alpha 2,6)$-sialylated glycoproteins, whereas both ( $\alpha 2.3)$ - and ( $\alpha 2.6)$-linked sialic acids are present on mucin-1, FAS, and XO (Table 1).

Glycosylation of XO was not suspected (Mather, 2000) until Picariello et al. (2008) provided evidence for the presence of N-glycans in human XO. Here we showed that XO from goat milk is also glycosylated as strongly revealed by PNA, SNA, and MALII lectins, thus accounting for the presence of sialic acid residues most likely in an O-linked sugar chain (Table 1). Moreover, a consistent probability for O-glycosylation at $\mathrm{Thr}_{207}, \mathrm{Thr}_{1069}$, and $\mathrm{Thr}_{1071}$ occurs in caprine $\mathrm{XO}$ sequence (accession number A1YZ34) when using the predictive software NetOGlyc 3.1 (http://www.cbs.dtu. $\mathrm{dk} /$ services/NetOGlyc; Table 2). In contrast, ConA lectin does not stain XO (Table 1). This result is in agreement with the absence of putative $\mathrm{N}$-glycosylation sites in the Capra hircus sequence (Table 2).
Fatty acid synthase plays a central role in de novo lipogenesis in mammals. Fatty acid synthase is a complex multifunctional enzyme consisting of 2 identical monomers of $250 \mathrm{kDa}$ containing 7 active sites. Only the dimer form is functional to catalyze all the reaction steps involved in the synthesis of long-chain fatty acids, primarily palmitate from acetyl-CoA and malonyl-CoA. Fatty acid synthase is a cytoplasmic enzyme. However, its close interaction with lipid raft domains involving the membrane protein caveolin-1 has been recently demonstrated (Di Vizio et al., 2008) and may explain the recurrent presence of this protein in MFGM extracts. Fatty acid synthase expression and activity are regulated by numerous factors (Baron et al., 2004). However, posttranslational regulation of FAS remains poorly documented. Data exist on nicotineinduced FAS phosphorylation (An et al., 2007), but there is no evidence of FAS glycosylation. Caprine FAS (accession number Q06B57) virtually possesses 2 sites of O-glycosylation at $\mathrm{Thr}_{983}$ and $\mathrm{Thr}_{2145}$ and 11 $\mathrm{N}$-glycosylation sites (Table 2). Like XO, FAS is not

Table 2. Prediction of N-glycosylation and O-GalNAc attachment sites in major goat milk fat globule membrane (MFGM) proteins ${ }^{1}$

\begin{tabular}{lllll}
\hline MFGM protein & Taxon & Uniprot ID & O-glycosylation & N-glycosylation \\
\hline Fatty acid synthase & Capra hircus & Q06B57 & T983; T2145 & N195; N851; N1237; N1294; \\
& & & N1481; N1719; N2000; N2041; \\
& & T2334; N2445; N2466 \\
Xanthine oxidase & Capra hircus & A1YZ34 & T207 T1069; T1071 & No sites \\
Xanthine oxidase & Bos taurus & P80457 & T179 & N904 \\
Butyrophilin & Capra hircus & A3EY52 & No sites & N54; N214 \\
Lactadherin & Bos taurus & Q95114 & T63; T133; T135 & N59; N227 \\
Adipophilin & Bos taurus & Q8HZM7 & T63; T133; T135; T420; & N316 \\
Adipophilin & Ovis aries & A6ZE99 & S443; S448; S449; S450 & \\
& & &
\end{tabular}

${ }^{1}$ Source of prediction of N-glycosylation: http://www.cbs.dtu.dk/services/NetNGlyc/. Source of prediction of O-GalNAc (mucin type) attachment sites: http://www.cbs.dtu.dk/services/NetOGlyc/. Sites with higher probability of N-glycosylation are indicated in bold. When not available in Capra hircus, Bos taurus, or Ovis aries, full-length sequences were used with predictive software.

${ }^{2}$ http://www.uniprot.org. 

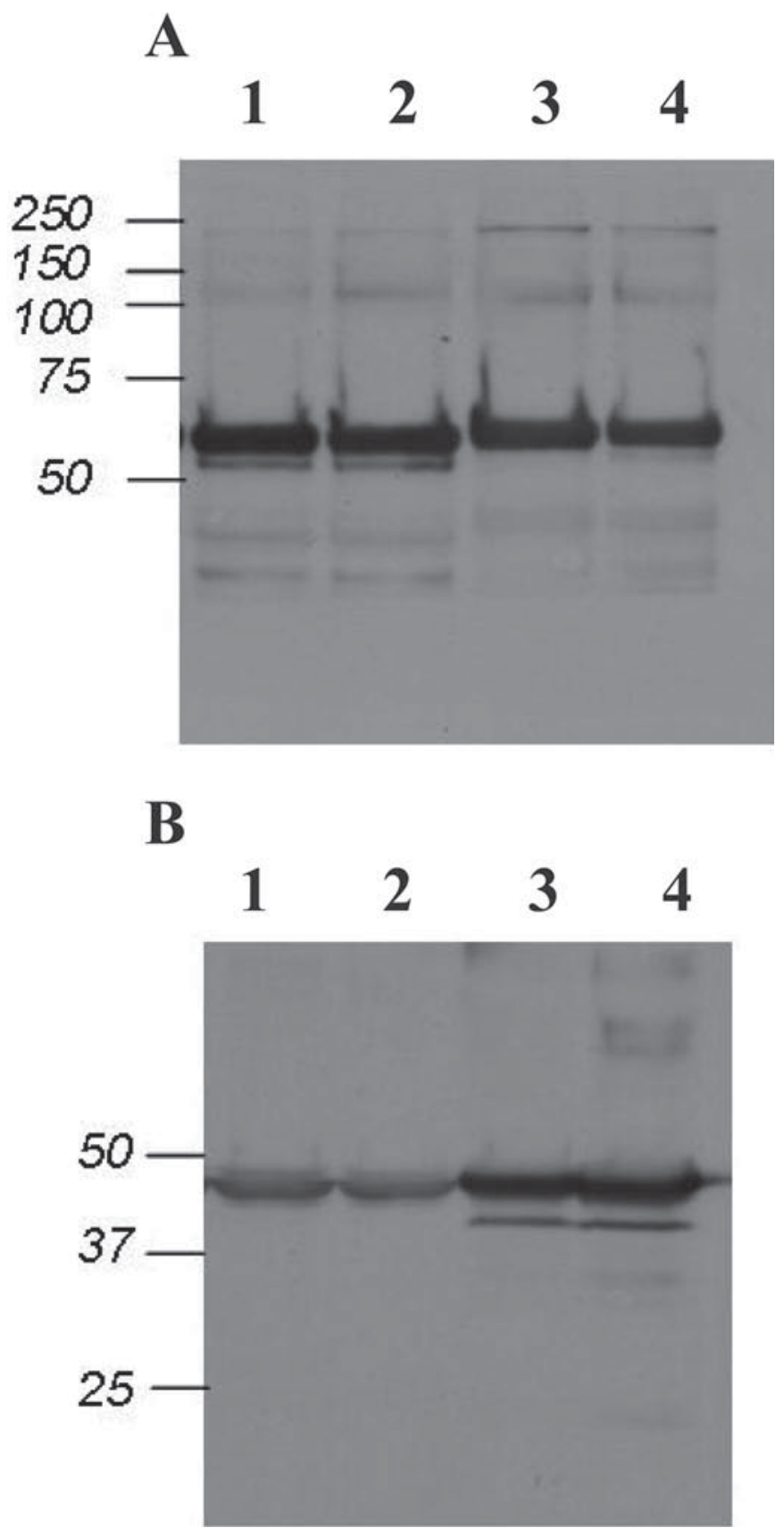

Figure 3. Characterization of butyrophilin and adipophilin from goat milk by immunoblotting. Twenty-five micrograms of milk fat globule membrane proteins were separated on $10 \%$ SDS-PAGE and electrotransferred onto nitrocellulose for immunoblotting with antibodies against A) bovine butyrophilin or B) mouse adipophilin, followed by appropriate secondary antibodies. Milk fat globule membrane proteins are from bovine (lanes 1-2) and caprine (lanes 3-4) milks. Positions of protein standards $(\mathrm{kDa})$ are indicated to the left of the panel.

visualized after PAS staining but can be revealed by PNA lectin, thus suggesting the existence of O-glycans on the protein. Fatty acid synthase is also recognized by sialic acid-binding lectins SNA and MALII but not by
ConA lectin, thus accounting for the existence of sialic acids most likely on an O-glycan chain (Table 1).

Bovine BTN1A1 is not known to be O-glycosylated, but is N-glycosylated at $\mathrm{N}_{56}$ and $\mathrm{N}_{216}$ (Mather, 2000). In agreement with this result, caprine BTN1A1 (accession number A3EY52) is not recognized by PNA, but is strongly stained by SNA and ConA lectin, thus confirming the absence of O-linked glycans and suggesting that $(\alpha 2.6)$-linked sialic acids chains are carried by N-linked carbohydrates. Interestingly, molecular weight deduced from primary sequences of bovine (accession number P18892) and caprine (accession number A3EY52) BTN1A1 are quite similar (59 kDa). Thus, the different apparent molecular weight in SDS-PAGE for bovine and caprine BTN1A1 after either PAS staining (Figure 2) or immunoblotting with specific antibodies (Figure 3A) may be because of differences in carbohydrate contents. In contrast, apparent molecular weight of ADRP, which is not supposed to be glycosylated (Mather, 2000), is comparable in MFGM extracts either from bovine or goat milks (Figure 3B).

$\alpha_{S 1}$-Casein deficiency in goats is associated with severe disorders of secretory pathways (Chanat et al., 1999). Indeed, an accumulation of immature proteins (mainly $\mathrm{CN}$ ) is observed in the absence of $\alpha_{\mathrm{S}_{1}} \mathrm{CN}$, leading to a dramatic distension of the ER. Protein N-glycosylation is actually a cotranslational event. First steps occur in the ER with addition of the $\mathrm{Glc}_{3} \mathrm{Man}_{9} \mathrm{GlcNAc}_{2}$ core to the protein backbone. After removal of the 2 outermost glucose residues, glycoproteins bind to either or both of the ER lectins calnexin and calreticulin. Further processing in the ER includes mannose removal and quality control. Correctly folded proteins are transportcompetent to Golgi compartments where additional glycosylation, including sialylation, occurs. Therefore, because the first steps of glycosylation take place in the $\mathrm{ER}$, it was of interest to study glycosylation patterns in goats with strong genotypes for $\alpha_{\mathrm{S1}^{-}} \mathrm{CN}$ compared with goats with null genotypes for $\alpha_{S_{1}}-\mathrm{CN}$, for which secretory pathways are severely affected (Chanat et al., 1999). In both genotypes, N- and O-glycosylation were comparable. In particular, no differences in protein sialylation could be observed between genotypes, thus indicating that Golgi events seem not to be affected by the $\alpha_{\mathrm{S} 1}-\mathrm{CN}$ polymorphism (data not shown).

Finally, we analyzed the sialic acid pattern of goat MFGM proteins at early, mid, and late lactation. Thirty micrograms of MFGM proteins were resolved by $6 \%$ SDS-PAGE, electrotransferred onto nitrocellulose, and probed with SNA and MALII lectins. No clear variation in sialylation of MFGM proteins throughout lactation was observed except for a discrete decrease of SNA and MALII lectins binding to mucin-1 protein from early to late lactation (data not shown). However, 
previously identified decreasing sialic acid content from colostrum to mature milk in the goat concerned the glycolipid fraction and especially gangliosides (Puente et al., 1994).

\section{CONCLUSIONS}

Although much attention has been paid among species to mucins because of their prominent role in preventing infections (Schroten et al., 1993), limited information was available to date on nonmucin MFGM proteins from goat milk. We provide here for the first time a thorough description, including carbohydrate gross composition, of MFGM proteins from goat milk. A prominent difference between the cow and the goat species was observed for LDH. Unlike its bovine counterpart, which consists of 2 differentially processed polypeptide chains, it appeared that LDH from goat milk consists of a single $55-\mathrm{kDa}$ protein that can be visualized on SDS-PAGE either after Coomassie or PAS staining. Moreover, a relationship among $\alpha_{\mathrm{S} 1}-\mathrm{CN}$ genotype, fat globule size, and LDH expression strongly suggests a putative function for this protein in the milk fat secretion process. Attempts are now made to get more insight into the precise role of this protein in the fat globule secretion mechanisms in the goat.

\section{REFERENCES}

An, Z., H. Wang, P. Song, M. Zhang, X. Geng, and M.-H. Zou. 2007. Nicotine-induced activation of AMP-activated protein kinase inhibits fatty acid synthase in 3T3L1 adipocytes: A role for oxidant stress. J. Biol. Chem. 282:26793-26801.

Barello, C., L. P. Garoffo, G. Montorfano, S. Zava, B. Berra, A. Conti, and M. G. Giuffrida. 2008. Analysis of major proteins and fat fractions associated with mare's milk fat globules. Mol. Nutr. Food Res. 52:1448-1456.

Baron, A., T. Migita, D. Tang, and M. Loda. 2004. Fatty acid synthase: A metabolic oncogene in prostate cancer? J. Cell. Biochem. 91:47-53.

Boehm, G., and B. Stahl. 2007. Oligosaccharides from milk. J. Nutr. $137: 847 \mathrm{~S}-849 \mathrm{~S}$.

Campana, W. M., R. V. Josephson, and S. Patton. 1992. Presence and genetic polymorphism of an epithelial mucin in milk of the goat (Capra hircus). Comp. Biochem. Physiol. 103B:261-266.

Chanat, E., P. Martin, and M. Ollivier-Bousquet. 1999. Alpha(S1)casein is required for the efficient transport of beta- and kappacasein from the endoplasmic reticulum to the Golgi apparatus of mammary epithelial cells. J. Cell Sci. 112:3399-3412.

D'Ambrosio, C., S. Arena, A. M. Salzano, G. Renzone, L. Ledda, and A. Scaloni. 2008. A proteomic characterization of water buffalo milk fractions describing PTM of major species and the identification of minor components involved in nutrient delivery and defense against pathogens. Proteomics 8:3657-3666.

Daddaoua, A., V. Puerta, P. Requena, A. Martinez-Ferez, E. Guadix, F. Sanchez de Medina, A. Zarzuelo, M. D. Suarez, J. J. Boza, and O. Martinez-Augustin. 2006. Goat milk oligosaccharides are anti-inflammatory in rats with hapten-induced colitis. J. Nutr. 136:672-676.

Dewettinck, K., R. Rombaut, N. Thienpont, T. T. Le, K. Messens, and J. Van Camp. 2008. Nutritional and technological aspects of milk fat globule material. Int. Dairy J. 18:436-457.
Di Vizio, D., R. M. Adam, J. Kim, R. Kim, F. Sotgia, T. Williams, F. Demichelis, K. R. Solomon, M. Loda, M. A. Rubin, M. Lisanti, and M. R. Freeman. 2008. Caveolin-1 interacts with a lipid raftassociated population of fatty acid synthase. Cell Cycle 7:22572267.

Fortunato, D., M. G. Giuffrida, M. Cavaletto, L. P. Garoffo, G. Dellavalle, L. Napolitano, C. Giunta, C. Fabris, E. Bertino, A. Coscia, and A. Conti. 2003. Structural proteome of human colostral fat globule membrane proteins. Proteomics 3:897-905.

Haenlein, G. F. W. 2001. Past, present, and future perspectives of small ruminant dairy research. J. Dairy Sci. 84:2097-2115.

Hanayama, R., and S. Nagata. 2005. Impaired involution of mammary glands in the absence of milk fat globule EGF factor 8. Proc. Natl. Acad. Sci. USA 102:16886-16891.

Hvarregaard, J., M. H. Andersen Lars Berglund, J. T. Rasmussen, and T. E. Petersen. 1996. Characterization of glycoprotein PAS-6/7 from membranes of bovine milk fat globules. Eur. J. Biochem. 240:628-636.

Liu, C., A. K. Erickson, and D. R. Henning. 2005. Distribution and carbohydrate structures of high molecular weight glycoproteins, MUC1 and MUCX, in bovine milk. J. Dairy Sci. 88:4288-4294.

McManaman, J. L., T. D. Russel, J. Schaack, D. J. Orlicky, and H. Robenek. 2007. Molecular determinants of milk lipid secretion. J. Mammary Gland Biol. Neoplasia 12:259-268.

Martinez-Ferez, A., S. Rudloff, A. Guadix, C. A. Henkel, G. Pohlentz, J. J. Boza, E. M. Guadix, and C. Kunz. 2006. Goats' milk as a natural source of lactose-derived oligosaccharides: Isolation by membrane technology. Int. Dairy J. 16:173-181.

Mather, I. H. 2000. A review and proposed nomenclature for major proteins of the milk-fat globule membrane. J. Dairy Sci. 83:203247.

Neveu, C., A. Riaublanc, G. Miranda, J. F. Chich, and P. Martin. 2002. Is the apocrine milk secretion process observed in the goat species rooted in the perturbation of the intracellular transport mechanism induced by defective alleles at the alpha(s1)-Cn locus? Reprod. Nutr. Dev. 42:163-172.

Pallesen, L. T., L. Berglund, L. K. Rasmussen, T. E. Petersen, and J. T. Rasmussen. 2002. Isolation and characterization of MUC15, a novel cell membrane-associated mucin. Eur. J. Biochem. 269:2755-2763.

Pallesen, L. T., L. R. L. Pedersen, T. E. Petersen, C. R. Knudsen, and J. T. Rasmussen. 2008. Characterization of human mucin (MUC15) and identification of ovine and caprine orthologs. J. Dairy Sci. 91:4477-4483.

Patton, S. 1999. Some practical implications of the milk mucins. J. Dairy Sci. 82:1115-1117.

Patton, S. 2001. MUC1 and MUC-X, epithelial mucins of breast and milk. Adv. Exp. Med. Biol. 501:35-45.

Petrunkina, A. M., A. Lakamp, M. Gentzel, M. Ekhlasi-Hundrieser, and E. Topfer-Petersen. 2003. Fate of lactadherin P47 during post-testicular maturation and capacitation of boar spermatozoa. Reproduction 125:377-387.

Picariello, G., P. Ferranti, G. Mamone, P. Roepstorff, and F. Addeo. 2008. Identification of N-linked glycoproteins in human milk by hydrophilic interaction liquid chromatography and mass spectrometry. Proteomics 8:3833-3847.

Puente, R., L. A. Garcia-Pardo, R. Rueda, A. Gil, and P. Hueso. 1994. Changes in ganglioside and sialic acid contents of goat milk during lactation. J. Dairy Sci. 77:39-44.

Reinhardt, T. A., and J. Lippolis. 2006. Bovine milk fat globule membrane proteome. J. Dairy Res. 73:406-416.

Reinhardt, T. A., and J. D. Lippolis. 2008. Developmental changes in the milk fat globule membrane proteome during the transition from colostrum to milk. J. Dairy Sci. 91:2307-2318.

Robenek, H., O. Hofnagel, I. Buers, S. Lorkowski, M. Schnoor, M. J. Robenek, H. Heid, D. Troyer, and N. J. Severs. 2006a. Butyrophilin controls milk fat globule secretion. Proc. Natl. Acad. Sci. USA 103:10385-10390.

Robenek, H., O. Hofnagel, I. Buers, M. J. Robenek, D. Troyer, and N. J. Severs. 2006b. Adipophilin-enriched domains in the ER membrane are sites of lipid droplet biogenesis. J. Cell Sci. 119:4215-4224. 
Sacchi, P., A. Caroli, E. Cauvin, S. Maione, S. Sartore, D. Soglia, and R. Rasero. 2004. Analysis of the MUC1 gene and its polymorphism in Capra hircus. J. Dairy Sci. 87:3017-3021.

Schroten, H. 1998. The benefits of human milk fat globule against infection. Nutrition 14:52-53.

Schroten, H., R. Plogmann, F. G. Hanisch, J. Hacker, R. Nobis-Bosch, and V. Wahn. 1993. Inhibition of adhesion of S-fimbriated E. coli to buccal epithelial cells by human skim milk is predominantly mediated by mucins and depends on the period of lactation. Acta Paediatr. 82:6-11.
Shi, J. L., Y. Shi, L. N. Waehrens, J. T. Rasmussen, C. W. Heegaard, and G. E. Gilbert. 2006. Lactadherin detects early phosphatidylserine exposure on immortalized leukemia cells undergoing programmed cell death. Cytometry A 69A:1193-1201.

Spitsberg, V. L. 2005. Bovine milk fat globule membrane as a potential nutraceutical. J. Dairy Sci. 88:2289-2294.

Varki, A. 2007. Glycan-based interactions involving vertebrate sialicacid-recognizing proteins. Nature 446:1023-1029. 